\title{
Faeco-prevalence of Campylobacter jejuni in urban wild birds and pets in New Zealand
}

Vathsala Mohan ${ }^{1,2}$

\begin{abstract}
Background: Greater attention has been given to Campylobacter jejuni (C. jejuni) prevalence in poultry and ruminants as they are regarded as the major contributing reservoirs of human campylobacteriosis. However, relatively little work has been done to assess the prevalence in urban wild birds and pets in New Zealand, a country with the highest campylobacteriosis notification rates. Therefore, the aim of the study was to assess the faeco-prevalence of $\mathcal{C}$. jejuni in urban wild birds and pets and its temporal trend in the Manawatu region of New Zealand.

Findings: A repeated cross-sectional study was conducted from April 2008 to July 2009, where faecal samples were collected from 906 ducks, 835 starlings, 23 Canadian goose, 2 swans, 2 pied stilts, 498 dogs and 82 cats. The faecoprevalence of C. jejuni was 20\% in ducks, $18 \%$ in starlings, $9 \%$ in Canadian goose, $5 \%$ in dogs and $7 \%$ in cats. The faecoprevalence of $C$. jejuni was relatively higher during warmer months of the year in ducks, starlings and dogs while starlings showed increased winter prevalence. No such trend could be assessed in Canadian goose, swans, pied stilts and cats as samples could not be collected for the entire study period from these species.

Conclusions: This study estimated the faeco-prevalence of $C$. jejuni in different animal species where the prevalence was relatively high during warmer months in general. However, there was relative increase in winter prevalence in starlings. The urban wild bird species and pets may be considered potential risk factors for human campylobacteriosis in New Zealand, particularly in small children.
\end{abstract}

Keywords: Campylobacter spp, C. jejuni, Urban wild birds, Pets, Faeco-prevalence

\section{Background}

Campylobacter spp. is one of the major causes of bacterial gastroenteritis worldwide [1], where the majority of the human campylobacteriosis cases are attributed to C. jejuni with C. coli and C. upsaliensis being isolated in small proportion of human cases [2-5]. The disease is self-limiting, however, severe sequelae such as Guillain-Barre syndrome and reactive arthritis have been recorded occasionally [6]. The risk of human campylobacteriosis arising from food source has been extensively studied [7-11] where the risk of environmental exposure to faecal material from livestock, including wild birds, ruminants and pet animals is under studied $[12,13]$. Different exposure pathways have to be elucidated to better understand the relative contributions of various environmental factors towards human

\footnotetext{
Correspondence: lingvathsala@gmail.com

${ }^{1}$ Institute of Veterinary, Animal and Biomedical Sciences, Massey University, Palmerston North, New Zealand

${ }^{2}$ Current address: Post-Doctoral Scientist, AgResearch, Grasslands, Palmerston North, New Zealand
}

campylobacteriosis. Previous studies on urban wild birds and pet animals have identified the link between the $C$. jejuni populations from wild birds and human campylobacteriosis [14]. Urban wild birds including ducks, goose, swans and starlings cause enormous faecal contamination of the environment where population biology studies of Campylobacter conducted in ducks, goose and starlings have shown that these bird species cannot be excluded from being contributing sources of Campylobacter infection for farm animals and humans $[15,16]$. Therefore, the present study was aimed to estimate the faeco-prevalence of C. jejuni in ducks, goose, swans and starlings from urban wild bird species and from dogs and cats in the Manawatu region of lower north island of New Zealand.

\section{Findings}

Research aim

The research aim was to estimate the faeco-prevalence of Campylobacter and C. jejuni in urban wild birds and 
pets at different sampling sites and over different time periods.

\section{Methods}

\section{Study design}

A repeated cross sectional study was conducted for sixteen months from April 2008 to July 2009. Five public parkland sites within the city limits were selected for sampling duck, goose, swan and starling faecal material: The Square, Hokowhitu, Memorial Park, Massey University and The Esplanade; all sites had at least one duck pond. To calculate the sample size for the urban wild birds, the prevalence was assumed in the order of 30$35 \%$ based on the previous report [16]. Each of the five study sites was visited at monthly intervals for a period of 17 months, starting in March 2008, where an initial standardisation for sample collection, transport and culture was carried out during March 2008 sampling round. For dogs and cats 50\% design prevalence was assumed for the sample size calculations due to the wide range of prevalence estimates in the previous studies [17-21]. A 95\% level of confidence and a 5\% margin of error [22] were used for all the sample size calculations. Ten dog walk way areas within Manawatu region commonly used for dog walking were sampled: The Hokowhitu, The Esplanade, Coronation Park, Milverton Park, Bledisloe Park, Albert Street, Vogel Street, Railway Road, Fitzherbert Bridge and The Bridle Track and faecal samples were also collected from the dogs that visited the Massey University Small Animal Veterinary Clinic while they defecated. Cat faecal material was collected from the Massey University Small Animal Veterinary Clinic from those cats that attended the hospital for routine vaccination and deworming procedures and from cats belonging to staff and students of Massey University, one private veterinary clinic and a commercial cattery in the Manawatu region.

\section{Sample collection}

Each sampling site for urban wild birds and pets was visited once a month to collect faecal samples. At each sampling site fresh faecal material (moist and slimy; $\mathrm{n}=12$ per site) was collected from ducks from areas where the ducks rested while for the starlings nesting areas were identified at each sampling site and faecal samples $(\mathrm{n}=12$ per site) under each nesting area were collected during early morning hours and late evening hours. As the Canadian geese were sighted only during the months of August 2008, February, March, April and July 2009, samples could not be collected for the entire study. Likewise, swans were sighted only during the month of April 2008 and Pied stilts were sighted only during May 2008 sampling round and hence samples from these two species could not be collected for the entire study ( $\mathrm{n}=2$ each species). Similarly, samples could not be collected from cats for the entire study period as it was done for the ducks, dogs and starlings. A total of 906 samples from ducks, 835 from starlings and 23 from Canadian goose for urban wild birds and 498 from dogs $(n=3$ per site; $n=30$ per month and $\mathrm{n}=25$ from Massey University Small Animal Veterinary Clinic) and 82 (small animal clinic: $\mathrm{n}=77$; staff and students: $n=3$; cattery: $n=2$ ) from cats were collected in transport media (Amies charcoal, Fort Richards, Auckland) from the sampling sites. During few sampling rounds, it was not possible to collect a complete set of dog samples from the faecal bins as well as for ducks and starlings (Table 1).

\section{Bacterial isolation and DNA preparation}

Faecal samples from all sources were transported immediately to the Hopkirk Research Institute Laboratory on the Massey University campus at Palmerston North and were directly streaked onto modified charcoal cefoperazone - deoxycholate (mCCDA) (Fort Richards, Auckland) plates. The inoculated plates were incubated for 48 hours at $42^{\circ} \mathrm{C}$ in a microaerophilic chamber (MACS VA500 Microaerophilic workstation, Don Whitley Scientific) and the presumptive Campylobacter colonies were subcultured onto blood agar plates (horse lysed blood agar, Fort Richards) for 48 hours at $42^{\circ} \mathrm{C}$. The pure colonies isolated from the horse blood agar plates tested for oxidase reduction (oxidase strips, Fort Richards, Auckland), indicated by a purple colouration, were transferred to $1 \mathrm{~mL}$ of $2 \%$ (weight/volume) Chelex solution (SigmaAldrich) in distilled water and boiled at $100^{\circ} \mathrm{C}$ on heating blocks for 10 minutes. These were then cooled to room temperature, centrifuged at $13,000 \mathrm{rpm}$ for 10 minutes and the supernatants were collected in fresh sterile eppendorf tubes and stored at $-20^{\circ} \mathrm{C}$.

\section{Polymerase chain reaction (PCR)}

Isolates were characterised for Campylobacter spp. and C. jejuni using monoplex PCR using 16s rRNA gene primers for Campylobacter spp. and the membrane associated protein A (mapA) gene primers for C. jejuni, $[13,23]$ respectively. Campylobacter genus primer sequences were: forward 5' GGATGACACTTTTCGGAGC 3'; reverse 3' CATTGTAGCACGTGTGTC 3'. C. jejuni primer sequences were: forward $5^{\prime}$ CTTGGCTTGAAA 'TTTGCTTG 3' and reverse 3' GCTTGGTGCGGATTG TAAA $5^{\prime}$. The PCR conditions consisted $96^{\circ} \mathrm{C}$ for $2 \mathrm{mi}-$ nutes for initial denaturation, $96^{\circ} \mathrm{C}$ for 30 seconds, primer annealing at $56^{\circ} \mathrm{C}$ for 30 seconds, and extension at $72^{\circ} \mathrm{C}$ for 30 seconds, with a final extension for 4 minutes for 35 cycles. The PCR reaction mix (Invitrogen) was prepared with $2 \mu \mathrm{L} 10 \mathrm{x}$ PCR buffer (final concentration 1x); $2 \mu \mathrm{L}$ dNTPs (final concentration $2 \mathrm{mM}$ ); magnesium chloride 1 $\mu \mathrm{L}$, (final concentration $2.5 \mathrm{mM}$ ); primers $2 \mu \mathrm{L}$ each (final concentration $1 \mathrm{mM}$ ); Taq DNA polymerase $0.2 \mu \mathrm{L}$ (final 
Table 1 Overall faeco-prevalence estimates of Campylobacter and C. jejuni in duck, starling, goose, dog and cat faecal material

\begin{tabular}{|c|c|c|c|}
\hline Species & $n$ & $\begin{array}{l}\text { Campylobacter positive } \\
(\% ; 95 \% \mathrm{Cl})\end{array}$ & $\begin{array}{l}\text { C. jejuni positive } \\
(\% ; 95 \% \mathrm{Cl}) \\
\end{array}$ \\
\hline Overall - urban wild birds & 1,768 & $33(19-51)$ & $19(17-21)$ \\
\hline Ducks & $906(n=12 \text { per site })^{*}$ & $29(26-32)$ & $20(18-23)$ \\
\hline Starlings & $835(n=12 \text { per site })^{*}$ & $41(38-45)$ & $18(16-21)$ \\
\hline Geese & $23(\mathrm{n}=5 \text { per month })^{\S}$ & $9(11-29)$ & $9(11-29)$ \\
\hline Pied stilt & $2^{\gamma}$ & $50(1-98)$ & $0(0-91)$ \\
\hline Swan & $2^{\gamma}$ & $50(1-98)$ & $0(0-91)$ \\
\hline Overall - pets & 580 & $17(14-20)$ & $7(5-9)$ \\
\hline Dogs & $498(n=3 \text { per site })^{*}$ & $13(10-16)$ & $5(4-8)$ \\
\hline Cats & 82 & $9(4-17)$ & $7(3-15)$ \\
\hline
\end{tabular}

$\mathrm{n}$ : Number of samples.

$\mathrm{Cl}$ : Confidence interval.

$\mathrm{n}$ : Number of samples.

$\mathrm{Cl}$ : Confidence interval.

*: Ducks: For sampling rounds April 2008 to July 2008, a complete set of 12 samples could not be collected from all sites and for August 2008 sampling round: it was not possible to collect 12 samples from the Hokowhitu sampling site.

s: Geese: August 2008 sampling round: only two samples could be collected from the Hokowhitu sampling site.

$\checkmark$ : During sampling rounds April 2008 and May 2008 two swans and two pied stilts were sighted at the Massey University sampling site and samples were collected from them.

¥: Dogs: January 2009 sampling round: No samples could be collected from the Milverton Park site and only one sample could be collected from Coronation Park for the June 2009 sampling round. A total of 25 samples were collected from small animal clinic, Massey University.

concentration 1 unit per reaction); DNA $2 \mu \mathrm{L}$ (final concentration $10 \mathrm{ng}$ per $\mu \mathrm{L}$ ). The reaction mix was made up to $20 \mu \mathrm{L}$ with distilled water. The amplicons were examined by agarose gel electrophoresis with results captured using a Bio-Rad gel documentation system (Life Science Group, Canada). The isolates were tested only for C. jejuni as the main aim of the project was to characterise $C$. jejuni from urban wild birds and pets and hence other nonjejuni Campylobacters were not characterised.

\section{Results}

Faeco-prevalence of Campylobacter spp. and C. jejuni

The overall faeco-prevalence of Campylobacter spp. in the sampled urban wild birds was 33\% (95\% confidence interval [CI] 19 to 51\%) and of C. jejuni was 19\% (CI 17 to $21 \%$ ). The overall Campylobacter and C. jejuni prevalence for pets were $17 \%$ (CI 14 to 20\%) and 7\% (CI 5 to $9 \%$ ), respectively (Table 1 ).

\section{Faeco-prevalence over time}

Overtime the faeco-prevalence of Campylobacter spp. and $C$. jejuni differed significantly between dogs, ducks and starlings. The data from goose, swans, pied stilts and cats could not be compared with other species due to small sample sizes as well as unavailability of samples for the entire study. Hence an overall faeco-prevalence was estimated for these species and presented in Table 1. The general trend was that the faeco-prevalences of both Campylobacter and C. jejuni were relatively high during warmer months (September, October, November, and
January) over the cooler months. However, there was an increase in the Campylobacter faeco-prevalence in starlings during the cooler months (April, May, June and July), Figure 1.

\section{Faeco-prevalence at different sampling sites}

The Canadian goose were sighted only in the Hokowhitu sampling site where other sites had only ducks and therefore the faeco-prevalence of Campylobacter and $C$. jejuni reported in the study for goose represents only the Hokowhitu sampling site. Likewise swans and pied stilts were sighted only at Massey University sampling site, hence the prevalence represents only Massey University sampling site. It is difficult to categorise the sampling sites for cats as the majority of the samples were collected from the small animal veterinary clinic. The prevalence estimates for different sampling sites for ducks and starlings and dogs are presented in Tables 2 and 3 , respectively. The Campylobacter spp. as well as C. jejuni faeco-prevalence in sites including The Esplanade, Memorial park and The Square were found to be relatively high compared with The Hokowhitu and Massey University sites, however, the starlings from The Hokowhitu site showed relatively high prevalence over ducks from the same site. The faeco-prevalence of Campylobacter spp. in dogs in The Esplanade, Bledisloe Park, Fitzherbert Bridge and the Milverton Park were relatively higher than that of other sites while the dog samples from the Bledisloe Park and The Bridle Track showed high C. jejuni faecoprevalence compared to other sites. 


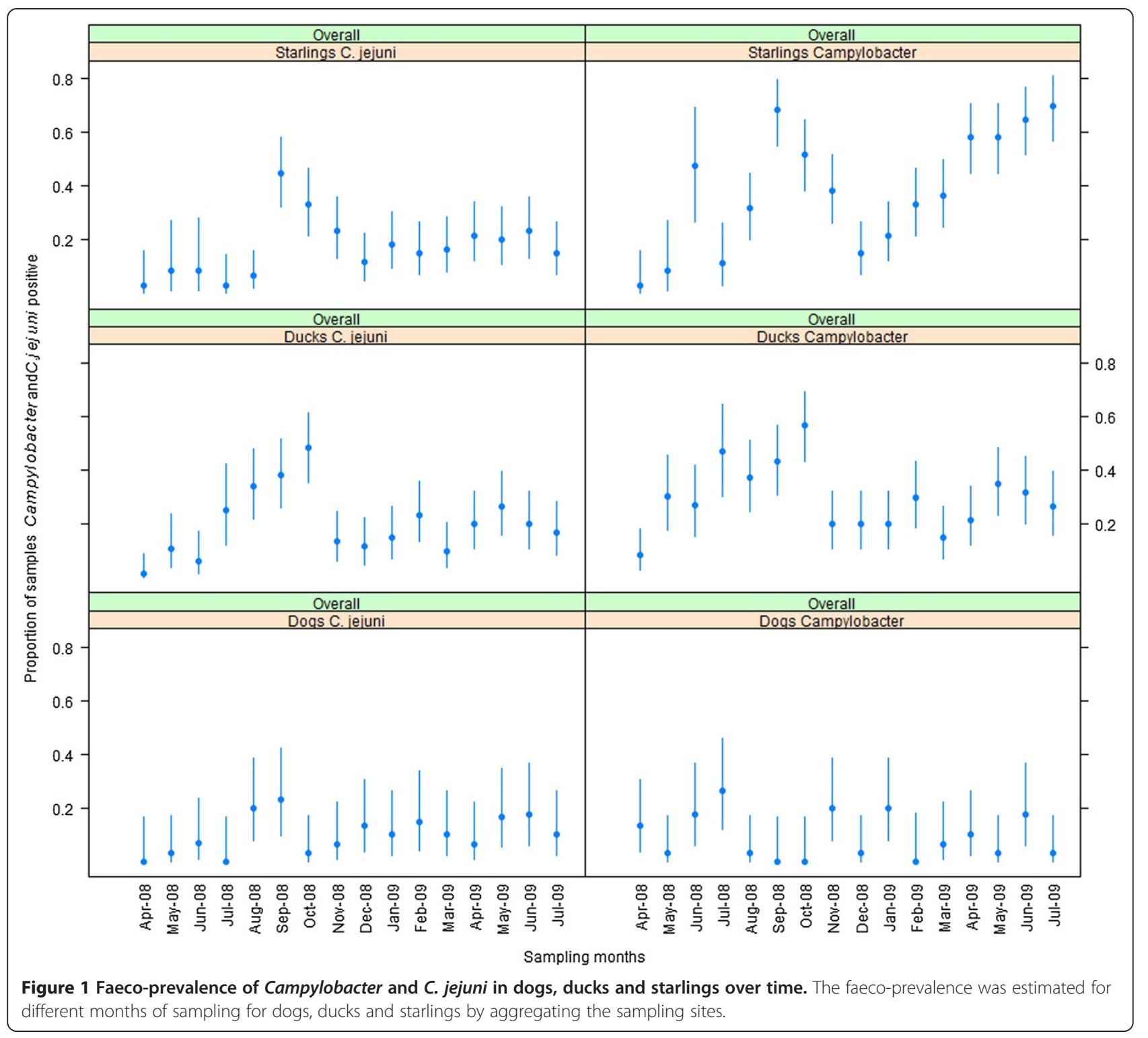

\section{Discussion}

Generally birds are referred to as natural reservoirs of Campylobacter spp. [2] and wild birds are known vectors of transmitting Campylobacter spp. to poultry, cattle and humans [24-26]. Similarly, pet ownership (particularly dogs and cats) has been identified as a risk factor for human campylobacteriosis particularly among small children and infants $[27,28]$. The aim of this study was to estimate the faeco-prevalence of Campylobacter spp. and C. jejuni in urban wild birds,

Table 2 Faeco-prevalence estimates of Campylobacter and C. jejuni in ducks and starlings at different sampling sites

\begin{tabular}{lllll}
\hline Sampling sites & $\begin{array}{l}\text { Ducks Campylobacter positive } \\
\text { (\%; 95\% Cl) }\end{array}$ & $\begin{array}{l}\text { Ducks C. Jejuni positive } \\
\text { (\%; 95\% Cl) }\end{array}$ & $\begin{array}{l}\text { Starlings Campylobacter positive } \\
\text { (\%; 95\% Cl) }\end{array}$ & $\begin{array}{l}\text { Starlings C. Jejuni positive } \\
\text { (\%; 95\% Cl) }\end{array}$ \\
\hline The Esplanade & $38(31-45)$ & $25(19-32)$ & $48(40-56)$ & $25(18-32)$ \\
The Hokowhitu & $20(15-27)$ & $17(12-23)$ & $39(31-47)$ & $13(8-19)$ \\
Memorial park & $32(26-40)$ & $22(16-29)$ & $48(40-56)$ & $22(16-30)$ \\
Massey University & $22(16-29)$ & $15(10-21)$ & $36(29-44)$ & $13(8-19)$ \\
The Square & $34(27-42)$ & $24(18-31)$ & $37(30-45)$ & $20(14-27)$ \\
\hline
\end{tabular}

Cl: Confidence interval. 
Table 3 Faeco-prevalence estimates of Campylobacter and C. jejuni in dogs at different sampling sites

\begin{tabular}{lll}
\hline Sampling sites & $\begin{array}{l}\text { Dogs Campylobacter } \\
\text { positive } \\
\text { (\%; 95\% Cl) }\end{array}$ & $\begin{array}{l}\text { Dogs C. jejuni } \\
\text { positive } \\
\text { (\%; 95\% Cl) }\end{array}$ \\
\hline Albert Street & $8(2-18)$ & $6(1-16)$ \\
Bledisloe Park & $18(9-31)$ & $10(3-21)$ \\
The Bridle Track & $10(3-21)$ & $8(2-18)$ \\
Coronation Park & $6(1-16)$ & $4(0.4-13)$ \\
The Esplanade & $25(14-40)$ & $4(0.4-13)$ \\
Fitzherbert Bridge & $16(7-29)$ & $6(1-16)$ \\
The Hokowhitu & $6(1-16)$ & $6(1-16)$ \\
Milverton Park & $12(0.4-24)$ & $4(0.4-13)$ \\
Railway Road & $4(0.4-13)$ & $4(0.4-13)$ \\
Vogel Street & $10(3-21)$ & $2(0.1-10)$ \\
\hline
\end{tabular}

$\mathrm{Cl}=$ Confidence interval.

dogs and cats at different sites and over different months of sampling.

The overall faeco-prevalence of Campylobacter spp. was estimated to be $33 \%$ (95\% CI 19 - 51\%) for wild birds. The Campylobacter faeco-prevalence in urban wild birds is relatively high compared to migrating birds (22\%) and relatively low compared to aquatic birds that feed on invertebrates (50\%) [25]. However, the estimated faeco-prevalence of Campylobacter spp. (41\%) in European starlings was relatively high compared to previous studies that ranged from $33 \%$ to $40 \%$ [16,24,25,29], where the prevalence of Campylobacter spp. in starlings is noted to be high in general $[16,29]$. In contrast, the faeco-prevalence estimates of C. jejuni in ducks (20\%) and starlings (18\%) were relatively low compared with previous studies (ducks, 30.6\%; starlings (29.9\%) [16,25,29]. The differences in the prevalence estimates could be attributed to several factors including sample size, sampling techniques, type of samples tested, age of fecal material and sensitivity of the culture techniques [30,31].

The overall faeco-prevalence of Campylobacter spp. in dogs was $13 \%$ (95\% CI $10 \%$ to $16 \%$ ) which is relatively low compared with previous prevalence studies that reported prevalence estimates ranging from $18 \%$ to $72 \%$ [32-40] and $9 \%$ of samples from cats were positive for Campylobacter spp.. The overall $C$. jejuni faeco-prevalence was $5 \%$ (95\% CI $4 \%$ to $8 \%$ ) in dogs and 7\% (95\% CI 3\% to 15\%) in cats, while the prevalence of $C$. jejuni has been reported to be $3 \%$ to $40 \%$ [41-45] in dogs and $76 \%$ in cats [40]. In the present study faecal samples were collected from dog faecal bins while samples have been generally collected from the rectum using swabs in the majority of the studies which may have resulted in low prevalence estimates as Campylobacter is micro-aerophilic. When Campylobacter spp. are exposed to adverse conditions the organisms enter a state of existence but non-culturable forms which directly impacts the recovery rate of Campylobacter spp. from the faecal and/or environmental samples in culture which in turn could have also influenced the recovery rate of Campylobacter in this study [46,47]. Furthermore, the survival of Campylobacter in dog faecal material is dependent on the prevailing environmental temperature and therefore this study may under-represent the true faecoprevalence of Campylobacter in dogs. It should be acknowledged that the faeco-prevalence in cats was based on a small sample of animals attending veterinary hospitals and therefore cannot be compared with the study of dog faeces and also these cats cannot be considered as the representative of the general cat population in NZ. However, as there are only few studies of Campylobacter spp. in cats, and none in New Zealand, the results have been reported here.

There was marked differences observed in the faecoprevalence of Campylobacter spp. as well as C. jejuni in dogs, ducks and starlings during different months of sampling. The prevalence estimates over time with the early spring peak in ducks was in agreement with one study [48] that was carried out in goose while few other studies [25,49] also identified shedding of Campylobacter spp. in the autumn at a greater level. The relatively increased faeco-prevalence during warmer months may be speculated to have an association with increased incidence rates of human campylobacteriosis in NZ during spring and summer. While increased autumn and winter shedding of Campylobacter cannot be ignored as there are reports of autumn-winter outbreaks $[50,51]$ that have been related with organic meat consumption, handling of pets with diarrhoea and farm visits during winter. It may be hypothesised that increased environmental contamination with wild birds' faecal material and contamination from the uncleansed dog faecal bins and/or dog faeces may be additional contributors to the winter outbreaks.

Although this study has estimated the faeco-prevalence of Campylobacter spp. in a country such as New Zealand that has the highest campylobacteriosis notification rates, it should be acknowledged that this study has a limitation that the study was conducted only for sixteen months. Furthermore, molecular typing of $C$. jejuni isolates from all species will aid in determining urban wild birds and pets as potential sources of human campylobacteriosis. Nonetheless, this study has provided some insights into the faeco-prevalence and the temporal trend of Campylobacter spp. and C. jejuni in urban wild birds and dogs which could be correlated with the seasonality of human campylobacteriosis in NZ context, particularly in small children that use these sampling sites for play.

\section{Conclusion}

This study estimated the faeco-prevalence of Campylobacter spp. and C. jejuni in urban wild birds (ducks, goose and starlings) and pets (dogs and cats) in the Manawatu 
region of lower north island of New Zealand. The faecoprevalence varied among months of sampling and at sampling sites where the warmer months showed increased prevalence with increased winter faeco-prevalence in starlings. This study has provided insights into the possibility of wild birds and pets being potential sources of Campylobacter to humans and other animal species and; the environmental faecal contamination being an important public health risk, particularly to the small children that use the sampling sites for play. However, typing Campylobacters further to different species level and genotyping the isolates by employing internationally recognised genotyping techniques such as multilocus sequence typing and antigenic (flaA-SVR and porA) typing at least for C. jejuni from urban wild birds and pets will provide valuable insights into (1) the role of these bird and animal species as vectors in the transmission of C. jejuni to humans and (2) the magnitude of their contribution towards human campylobacteriosis in NZ.

\section{Ethics statement}

This work did not involve animals.

\section{Competing interests}

The author declares that she has no competing interests.

\section{Authors' contributions}

VM carried out this work as in partial fulfilment of her PhD. VM carried out sampling, processing and all the laboratory work. VM prepared the manuscript.

\section{Acknowledgments}

This project was funded by the financial support from the Cross Departmental Research Pool (CDRP) funding (RM12467). I, Vathsala Mohan, thank Massey University Doctoral Scholarship and New Zealand International Doctoral Scholarship, New Zealand for funding my PhD study programme. Dr. Grant Hotter (Late), VM's supervisor, was actively involved in the work, including study design and died suddenly in 2009, who is remembered with gratitude for his contribution to this work. VM thanks Professor Mark Stevenson (University of Melbourne, Australia) for his guidance and his assistance in writing and his moral support. VM thanks the supervisors and staff of IVABS, Massey University for their guidance and help in the laboratory during her PhD work.

Received: 8 August 2014 Accepted: 11 December 2014

Published: 2 February 2015

\section{References}

1. Newell DG. Animal models of Campylobacter jejuni colonization and disease and the lessons to be learned from similar Helicobacter pylori models. J Appl Microbiol. 2001;90:57S-67.

2. Lee MD, Newell DG. Campylobacter in poultry: Filling an ecological niche. Avian Dis. 2006;50:1-9.

3. Lastovica AJ, Le Roux E. Optimal detection of Campylobacter spp. in stools. J Clin Pathol. 2003;56:480.

4. Goossens H, Pot B, Vlaes L, Van C, den Borre R, Van den Abbeele C, et al. Characterization and description of "Campylobacter upsaliensis" isolated from human feces. J Clin Microbiol. 1990;28:1039-46.

5. Labarca JA, Sturgeon J, Borenstein L, Salem N, Harvey SM, Lehnkering E, et al. Campylobacter upsaliensis: Another pathogen for consideration in the United States. Clin Infect Dis. 2002;34:e59-60.

6. Altekruse SF, Stern NJ, Fields PI, Swerdlow DL. Campylobacter jejuni-an emerging foodborne pathogen. Emerg Infect Dis. 1999;5:28-35.
7. Eberhart-Phillips J, Walker N, Garrett N, Bell D, Sinclair D, Rainger W, et al. Campylobacteriosis in New Zealand: results of a case-control study. J Epidemio Community Health. 1997;51:686-91.

8. Samuel MC, Vugia DJ, Shallow S, Marcus R, Segler S, McGivern T, et al. Epidemiology of sporadic Campylobacter infection in the United States and declining trend in incidence, FoodNet 1996-1999. Clin Infect Dis. 2004;38:S165-74

9. Siemer BL, Nielsen EM, On SLW. Identification and molecular epidemiology of Campylobacter coli isolates from human gastroenteritis, food, and anima sources by amplified fragment length polymorphism analysis and penner serotyping. Appl Environ Microbiol. 2005;71:1953-8.

10. Baker M, Wilson N, Ikram R, Chambers S, Shoemack P, Cook G. Regulation of chicken contamination urgently needed to control New Zealand's serious campylobacteriosis epidemic. N Z Med J. 2006;119:1243.

11. Sheppard SK, Dallas JF, Strachan NJC, MacRae M, McCarthy ND, Wilson DJ, et al. Campylobacter genotyping to determine the source of human infection. Clin Infect Dis. 2009:48:1072-8.

12. Savill M, Hudson A, Devane M, Garrett N, Gilpin B, Ball A. Elucidation of potential transmission routes of Campylobacter in New Zealand. Water Sci Technol. 2003;47:33-8.

13. Mullner P, Collins-Emerson JM, Midwinter AC, Carter P, Spencer SEF, van der Logt $P$, et al. Molecular epidemiology of Campylobacter jejuni in a geographically isolated country with a uniquely structured poultry industry. Appl Environ Microbiol. 2010;76:2145-54.

14. Gras LM, Smid JH, Wagenaar JA, Koene MGJ, Havelaar AH, Friesema IHM et al. Increased risk for Campylobacter jejuni and C. coli infection of pet origin in dog owners and evidence for genetic association between strains causing infection in humans and their pets. Epidemiol Infect. 2013;141:2526-35.

15. Colles FM, Ali JS, Sheppard SK, McCarthy ND, Maiden MCJ. Campylobacter populations in wild and domesticated Mallard ducks (Anas platyrhynchos) Environ Microbiol Rep. 2011;3:574-80.

16. Colles FM, Dingle KE, Cody AJ, Maiden MCJ. Comparison of Campylobacter populations in wild geese with those in starlings and free-range poultry on the same farm. Appl Environ Microbiol. 2008;74:3583-90.

17. Baker J, Barton MD, Lanser J. Campylobacter species in cats and dogs in South Australia. Aust Vet J. 1999;77:662-8.

18. Burnens AP, Angeloz-Wick B, Nicolet J. Comparison of Campylobacter carriage rates in diarrheic and healthy pet animals. Zentralbl Veterinarmed B. 1992;39:175-80.

19. Engberg J, On SLW, Harrington CS, Gerner-Smidt P. Prevalence of Campylobacter, Arcobacter, Helicobacter, and Sutterella spp. in human fecal samples as estimated by a reevaluation of isolation methods for Campylobacters. J Clin Microbiol. 2000;38:286-91.

20. Moser I, Rieksneuwhner B, Lentzsch P, Schwerk P, Wieler LH. Genomic Heterogeneity and O-Antigenic Diversity of Campylobacter upsaliensis and Campylobacter helveticus Strains Isolated from Dogs and Cats in Germany. J Clin Microbiol. 2001;39:2548-57.

21. Steinhauserova I, Fojtikova K, Klimes J. The incidence and PCR detection of Campylobacter upsaliensis in dogs and cats. Lett Appl Microbiol. 2000;31:209-12

22. Levy PS, Lemeshow S. Sampling of Populations Methods and Applications. London: Wiley Series in Probability and Statistics; 1999.

23. Linton D, Lawson AJ, Owen RJ, Stanley J. PCR detection, identification to species level, and fingerprinting of Campylobacter jejuni and Campylobacter coli direct from diarrheic samples. I Clin Microbiol. 1997:35:2568-72.

24. Waldenstrom J, Broman T, Carlsson I, Hasselquist D, Achterberg RP Wagenaar JA, et al. Prevalence of Campylobacter jejuni, Campylobacter lari, and Campylobacter coli in different ecological guilds and taxa of migrating birds. Appl Environ Microbiol. 2002;68:5911-7.

25. Craven SE, Stern NJ, Line E, Bailey JS, Cox NA, Fedorka-Cray P. Determination of the incidence of Salmonella spp., Campylobacter jejuni, and Clostridium perfringens in wild birds near broiler chicken houses by sampling intestinal droppings. Avian Dis. 2000;44:715-20.

26. Studer E, Luthy J, Hubner P. Study of the presence of Campylobacter jejun and C. coli in sand samples from four Swiss chicken farms. Res Microbiol. 1999;150:213-9.

27. Tenkate TD, Stafford RJ. Risk factors for Campylobacter infection in infants and young children: a matched case-control study. Epidemiol Infect. 2001;127:399-404. 
28. Fullerton KE, Ingram LA, Jones TF, Anderson BJ, McCarthy PV, Hurd S, et al. Sporadic Campylobacter infection in infants: a population-based surveillance case-control study. Pediatr Infect Dis J. 2007;26:19-24

29. Hughes LA, Bennett $M$, Coffey $P$, Elliott J, Jones TR, Jones RC, et al. Molecular epidemiology and characterisation of Campylobacter spp. isolated from wild bird populations in northern England. Appl Environ Microbiol. 2009;75:3007-15.

30. Brown PE, Christensen OF, Clough HE, Diggle PJ, Hart CA, Hazel S, et al. Frequency and spatial distribution of environmental Campylobacter spp. Appl Environ Microbiol. 2004;70:6501-11.

31. Stanley KN, Wallace JS, Currie JE, Diggle PJ, Jones K. Seasonal variation of thermophilic campylobacters in lambs at slaughter. J Appl Microbiol. 1998:84:1111-6.

32. Acke E, McGill K, Golden O, Jones BR, Fanning S, Whyte P. Prevalence of thermophilic Campylobacter species in household cats and dogs in Ireland. Vet Rec. 2009;164:44-7.

33. Acke E, Whyte $P$, Jones BR, McGill K, Collins JD, Fanning S. Prevalence of thermophilic Campylobacter species in cats and dogs in two animal shelters in Ireland. Vet Rec. 2006:158:51.

34. Aydin F, Atabay HI, Akan M. The isolation and characterization of Campylobacter jejuni subsp. jejuni from domestic geese (Anser anser). J Appl Microbiol. 2001;90:637-42.

35. Bender JB, Shulman SA, Averbeck GA, Pantlin GC, Stromberg BE. Epidemiologic features of Campylobacter infection among cats in the upper midwestern United States. J Am Vet Med Assoc. 2005;226:544-7.

36. Damborg P, Olsen KE, Moller Nielsen E, Guardabassi L. Occurrence of Campylobacter jejuni in Pets Living with Human Patients Infected with C. jejuni. J Clin Microbiol. 2004;42:1363-4.

37. Engvall EO, Brandstrom B, Andersson L, Baverud V, Trowald-Wigh G, Englund L. Isolation and identification of thermophilic Campylobacter species in faecal samples from Swedish dogs. Scand J Infect Dis. 2003;35:713-8.

38. Hald B, Pedersen K, Waino M, Jorgensen JC, Madsen M. Longitudinal study of the excretion patterns of thermophilic Campylobacter Spp. in young pet dogs in Denmark. J Clin Microbiol. 2004;42:2003-12.

39. Parsons BN, Cody AJ, Porter CJ, Stavisky JH, Smith JL, Williams NJ, et al. Typing of Campylobacter jejuni Isolates from Dogs by Use of Multilocus Sequence Typing and Pulsed-Field Gel Electrophoresis. J Clin Microbiol. 2009;47:3466-71

40. Sandberg M, Bergsjo B, Hofshagen M, Skjerve E, Kruse H. Risk factors for Campylobacter infection in Norwegian cats and dogs. Prev Vet Med. 2002:55:241-53.

41. Hald B, Madsen M. Healthy puppies and kittens as carriers of Campylobacter spp., with special reference to Campylobacter upsaliensis. J Clin Microbiol. 1997;35:3351-2.

42. Koene MGJ, Houwers DJ, Dijkstra JR, Duim B, Wagenaar JA. Simultaneous presence of multiple Campylobacter species in dogs. J Clin Microbiol. 2004;42:819-21.

43. Lopez CM, Giacoboni G, Agostini A, Cornero FJ, Tellechea DM, Trinidad JJ. Thermotolerant campylobacters in domestic animals in a defined population in Buenos Aires, Argentina. Prev Vet Med. 2002;55:193-200.

44. Tsai HJ, Huang HC, Lin CM, Lien YY, Chou CH. Salmonellae and campylobacters in household and stray dogs in northern Taiwan. Vet Res Commun. 2007:31:931-9

45. Workman SN, Mathison GE, Lavoie MC. Pet dogs and chicken meat as reservoirs of Campylobacter spp. in Barbados. J Clin Microbiol. 2005:43:2642-50.

46. Murphy C, Carroll C, Jordan KN. Environmental survival mechanisms of the foodborne pathogen Campylobacter jejuni. J Appl Microbiol. 2006;100:623-32.

47. Persson S, Olsen KEP. Multiplex PCR for identification of Campylobacter coli and Campylobacter jejuni from pure cultures and directly on stool samples. J Med Microbiol. 2005;54:1043-7.

48. Colles FM, McCarthy ND, Howe JC, Devereux CL, Gosler AG, Maiden MCJ. Dynamics of Campylobacter colonization of a natural host, Sturnus vulgaris (European starling). Environ Microbiol. 2009;11:258-67.

49. Broman T, Waldenstrom J, Dahlgren D, Carlsson I, Eliasson I, Olsen B. Diversities and similarities in PFGE profiles of Campylobacter jejuni isolated from migrating birds and humans. J Appl Microbiol. 2004;96:834-43.

50. Gillespie IA, O'Brien SJ, Adak GK, Tam CC, Frost JA, Bolton FJ, et al. Point source outbreaks of Campylobacter jejuni infection-are they more common than we think and what might cause them? Epidemiol Infect. 2003;130:367-75

51. Mughini Gras L, Smid JH, Wagenaar JA, de Boer AG, Havelaar AH, Friesema IHM, et al. Risk Factors for Campylobacteriosis of Chicken, Ruminant, and Environmental Origin: A Combined Case-control and source attribution analysis. PLoS One. 2012;7:e42599.

doi:10.1186/1756-0500-8-1

Cite this article as: Mohan: Faeco-prevalence of Campylobacter jejuni in urban wild birds and pets in New Zealand. BMC Research Notes 2015 8:1.

\section{Submit your next manuscript to BioMed Central and take full advantage of:}

- Convenient online submission

- Thorough peer review

- No space constraints or color figure charges

- Immediate publication on acceptance

- Inclusion in PubMed, CAS, Scopus and Google Scholar

- Research which is freely available for redistribution 